\title{
Role of carboxylate ion and metal oxidation state on the morphology and magnetic properties of nanostructured metal carboxylates and their decomposition products ${ }^{\dagger}$
}

\author{
APARNA GANGULY ${ }^{\mathrm{b}}$, RITUPARNA KUNDU, ${ }^{\mathrm{a}}$ KANDALAM V RAMANUJACHARY', \\ SAMUEL E LOFLAND ${ }^{\mathrm{d}}$, DIPANKAR DAS ${ }^{\mathrm{e}}, \mathrm{N}^{\mathrm{Y}}$ Y VASANTHACHARYA ${ }^{\mathrm{f}}$, \\ TOKEER AHMAD ${ }^{\mathrm{b}}$ and ASHOK K GANGULI ${ }^{\mathrm{a}} *$ \\ ${ }^{a}$ Department of Chemistry, Indian Institute of Technology, Hauz Khas, New Delhi 110016 \\ ${ }^{b}$ Department of Chemistry, Faculty of Natural Sciences, Jamia Millia Islamia, New Delhi 110025 \\ ${ }^{c}$ Department of Chemistry and Biochemistry, Center for Materials Research and Education, \\ Rowan University, 201 Mullica Hill Road, Glassboro, NJ 08028, USA \\ ${ }^{\mathrm{d}}$ Department of Physics, Center for Materials Research and Education, Rowan University, \\ 201 Mullica Hill Road, Glassboro, NJ 08028, USA \\ ${ }^{\mathrm{e}}$ UGC-DAE, Consortium for Scientific Research, LB-8, Sector-III, Bidhannagar, Kolkata 700098 \\ ${ }^{\mathrm{f}}$ Solid State and Structural Chemistry Unit, Indian Institute of Sciences, Bangalore 560012 \\ e-mail: ashok@chemistry.iitd.ernet.in
}

\begin{abstract}
Sub-micron rods and spheres of cobalt succinate sesquihydrate and iron succinate trihydrate/pentahydrate respectively have been synthesized by the reverse micellar route. These precursors are an excellent source for the synthesis of metal and metal oxide nanoparticles. Cubes of (edge length $\sim 150 \mathrm{~nm}) \mathrm{Fe}_{3} \mathrm{O}_{4}$ and elongated particles of $\mathrm{Fe}_{2} \mathrm{O}_{3}(\sim$ diameter of $200 \mathrm{~nm})$ were obtained. The role of oxidation state of the metal ion in controlling the morphology of the nanostructured dicarboxylates has been investigated. Rods with shorter length were obtained when longer chain dicarboxylate was used as ligand. Heating in nitrogen atmosphere also provided pure $\mathrm{Co}$ and $\alpha$-Fe nanoparticles. The Fe nanoparticles show nearly $100 \%$ superparamagnetism. Temperature-dependent magnetic studies show a Morin-like transition for $\mathrm{Fe}_{2} \mathrm{O}_{3}$ nanoparticles at $223 \mathrm{~K}$ and the Verwey transition at $115 \mathrm{~K}$ for $\mathrm{Fe}_{3} \mathrm{O}_{4}$ nanoparticles. $\mathrm{Co}_{3} \mathrm{O}_{4}$ nanoparticles showed antiferromagnetic ordering at $20 \mathrm{~K}$.
\end{abstract}

Keywords. Reverse micelles; Morin transition; metal carboxylates; Verwey transition.

\section{Introduction}

Hybrid inorganic-organic compounds are attracting interest as a class of materials that are well-suited for the incorporation of transition metal ions, especially in inorganic solids having porous networks. The use of organic moieties to build extended metalorganic nanostructures is currently being investigated on a large scale. These are found to be promising materials for applications in catalysis, separation, gas storage and molecular recognition. Several studies on single crystals of three-dimensional open framework structures complexed with metal ions obtained by hydrothermal method have been reported. ${ }^{1,2}$ Kinetic analysis on the thermal decompo-

\footnotetext{
${ }^{\dagger}$ Dedicated to Prof. C N R Rao on his 75th birthday

*For correspondence
}

sition of transition metal succinates obtained by coprecipitation method has also been reported, ${ }^{3}$ which led to either single crystalline $(0.01 \mathrm{~mm})$ or micronsized polycrystalline materials. We have been interested in the nanostructures of metal-organic-based systems. Earlier we have obtained nanorods of metal oxalates of several metals using the reverse micellar route. ${ }^{4-6}$ Reverse micelles have been widely used for the preparation of a variety of nanoparticles due to their ability to mix the reactants efficiently and to control the size of the nanoparticles. Here we use the succinate moiety to generate metal succinate nanostructures using the reverse micellar method.

These succinate metal-organic precursors were decomposed under different atmospheres to obtain pure metal and metal-oxide nanoparticles. We could obtain fine nanoparticles of maghemite, $\alpha-\mathrm{Fe}_{2} \mathrm{O}_{3}$, and magnetite, $\mathrm{Fe}_{3} \mathrm{O}_{4}$, by varying the conditions of 
decomposition of the succinate. We have also obtained nanoparticles of $\mathrm{Co}_{3} \mathrm{O}_{4}$ which is an important oxide used for electrochemical, magnetic and catalytic applications. We compared the magnetic properties of the metal succinate precursors and the oxide nanoparticles with those obtained by using metal oxalates as precursors. ${ }^{4}$

\section{Experimental}

Water soluble $\mathrm{Co}\left(\mathrm{NO}_{3}\right)_{2} \cdot 6 \mathrm{H}_{2} \mathrm{O}, \mathrm{Fe}\left(\mathrm{NO}_{3}\right)_{3} \cdot 9 \mathrm{H}_{2} \mathrm{O}$ and $\mathrm{FeCl}_{2} \cdot 4 \mathrm{H}_{2} \mathrm{O}$ were used as the metal ion sources. Microemulsion systems were prepared with $\mathrm{CTAB}$ as the surfactant, 1-butanol as the co-surfactant and isooctane as the hydrocarbon phase. Two microemulsions, one containing the metal ion and the other containing the succinate ion were mixed slowly. The product was collected by centrifugation and washed with a mixture of organic solvents to remove the surfactant and was allowed to dry at room temperature. Apart from the above synthesis using $\mathrm{Fe}\left(\mathrm{NO}_{3}\right)_{3}$. $9 \mathrm{H}_{2} \mathrm{O}$ and $\mathrm{Co}\left(\mathrm{NO}_{3}\right)_{2} \cdot 6 \mathrm{H}_{2} \mathrm{O}$, we also carried out a similar reaction using iron (II) chloride tetrahydrate as the starting reagent.

Powder X-ray diffraction (PXRD) studies were carried out on a Bruker D-8 Advance X-ray diffractometer using $\mathrm{Ni}$ filtered $\mathrm{CuK} \alpha$ radiation. Normal scans were recorded with a step of $0.02^{\circ}$ and a residence time of $1 \mathrm{~s}$. Infrared (IR) spectra of the succinates and oxides were recorded in the transmission mode in the range of $200-4000 \mathrm{~cm}^{-1}$ on a Nicolet Protégé 460 Fourier-transform infrared (FTIR) spectrometer with $\mathrm{KBr}$ discs. Thermogravimetric analysis (TGA) and differential Thermal analysis (DTA) were carried out on a Perkin-Elmer TGA-DTA instrument. Well-ground and dry samples were loaded under flowing nitrogen with a heating rate of $5 \%$ min. High resolution transmission electron microscopy (TEM) was recorded on a Technai $\mathrm{G}^{2} 20$ (FEI) electron microscope operated at $200 \mathrm{kV}$. TEM specimens were prepared by loading a drop of the ultrasonically dispersed sample in ethanol on a carbon-coated copper grid and dried in air. Magnetization studies of the metal succinates and the metal oxides were measured at temperatures ranging from 5 to $300 \mathrm{~K}$, in applied fields of up to $10 \mathrm{kOe}$ with a Quantum Design Physical Properties Measurement System. Magnetisation studies for $\mathrm{Fe}$ nanoparticles were carried out on a Lakeshore Model 7400 VSM. Mössbauer measurements were carried out at room temperature with a 512-channel Mössbauer spec- trometer operating in constant acceleration mode. A $10 \mathrm{mCi}{ }^{57} \mathrm{Co}$ in $\mathrm{Rh}$ matrix was used as the radioactive source. The spectrometer was calibrated with a $12 \mu \mathrm{m}$ thick natural iron foil of high purity.

\section{Results and discussion}

PXRD patterns of the as-prepared metal succinates showed the amorphous nature of these compounds. The samples were heated up to $200^{\circ} \mathrm{C}$ in stages to improve the crystallinity, but no significant change was observed in the PXRD pattern. The complexation of the metal to the ligand was confirmed by the characteristic IR bands. Bands corresponding to $3700-2850 \mathrm{~cm}^{-1}$ (presence of $\mathrm{O}-\mathrm{H}$ bond), $1599 \mathrm{~cm}^{-1}$ $\left(\mathrm{C}=\mathrm{O}\right.$ group), $670 \mathrm{~cm}^{-1}(\mathrm{Co}-\mathrm{O})$ and $560 \mathrm{~cm}^{-1}(\mathrm{Fe}-\mathrm{O})$ were observed.

TEM studies of cobalt succinate dihydrate showed rods of $\sim 500 \mathrm{~nm}$ length and $50 \mathrm{~nm}$ diameter (figure 1). In our earlier reports, ${ }^{4-6}$ we found that almost all metal oxalates, prepared by a similar reverse micellar route led to $M$ (II) oxalates with rod-like structures except for cerium oxalate ${ }^{7}$ where we observed spherical particles.

TEM studies of iron (III) succinate synthesized from $\mathrm{Fe}\left(\mathrm{NO}_{3}\right)_{3} \cdot 9 \mathrm{H}_{2} \mathrm{O}$ showed spherical particles of size $\sim 150-200 \mathrm{~nm}$ (figure 2a). Mössbauer study was carried out to confirm the oxidation state (O.S.) of

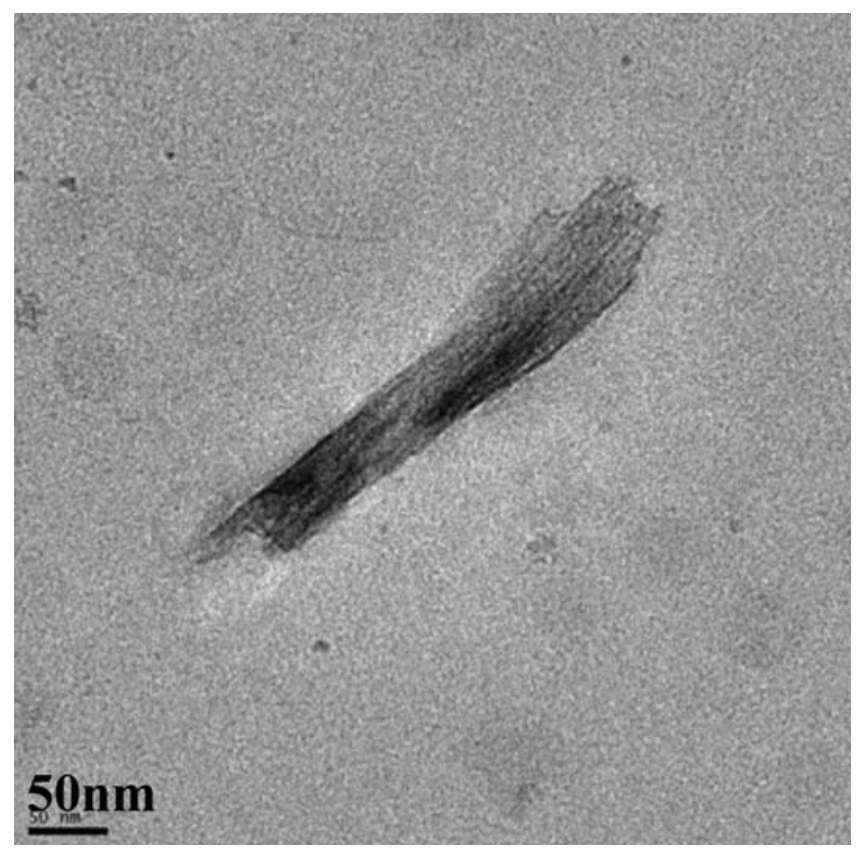

Figure 1. TEM micrograph of cobalt succinate dihydrate at room temperature. 
Fe (figure 2b). The isomer shift values are consistent with trivalent iron in octahedral geometry. It is thus expected that due to the +III O.S. of the metal ion, the ratio of metal ion to ligand required for charge neutralization would be $2: 3$. This ratio of metal to ligand results in the formation of spherical particles instead of a rod-like structure, which would normally require a $1: 1$ ratio of metal ion: ligand as shown in earlier studies on metal oxalates ${ }^{4,8}$.

In an attempt to further investigate the role of oxidation state of the metal ion, we used $\mathrm{FeCl}_{2} \cdot 4 \mathrm{H}_{2} \mathrm{O}$ as the starting reagent instead of $\mathrm{Fe}\left(\mathrm{NO}_{3}\right)_{3}$. The PXRD pattern and IR spectrum of the metal succi-
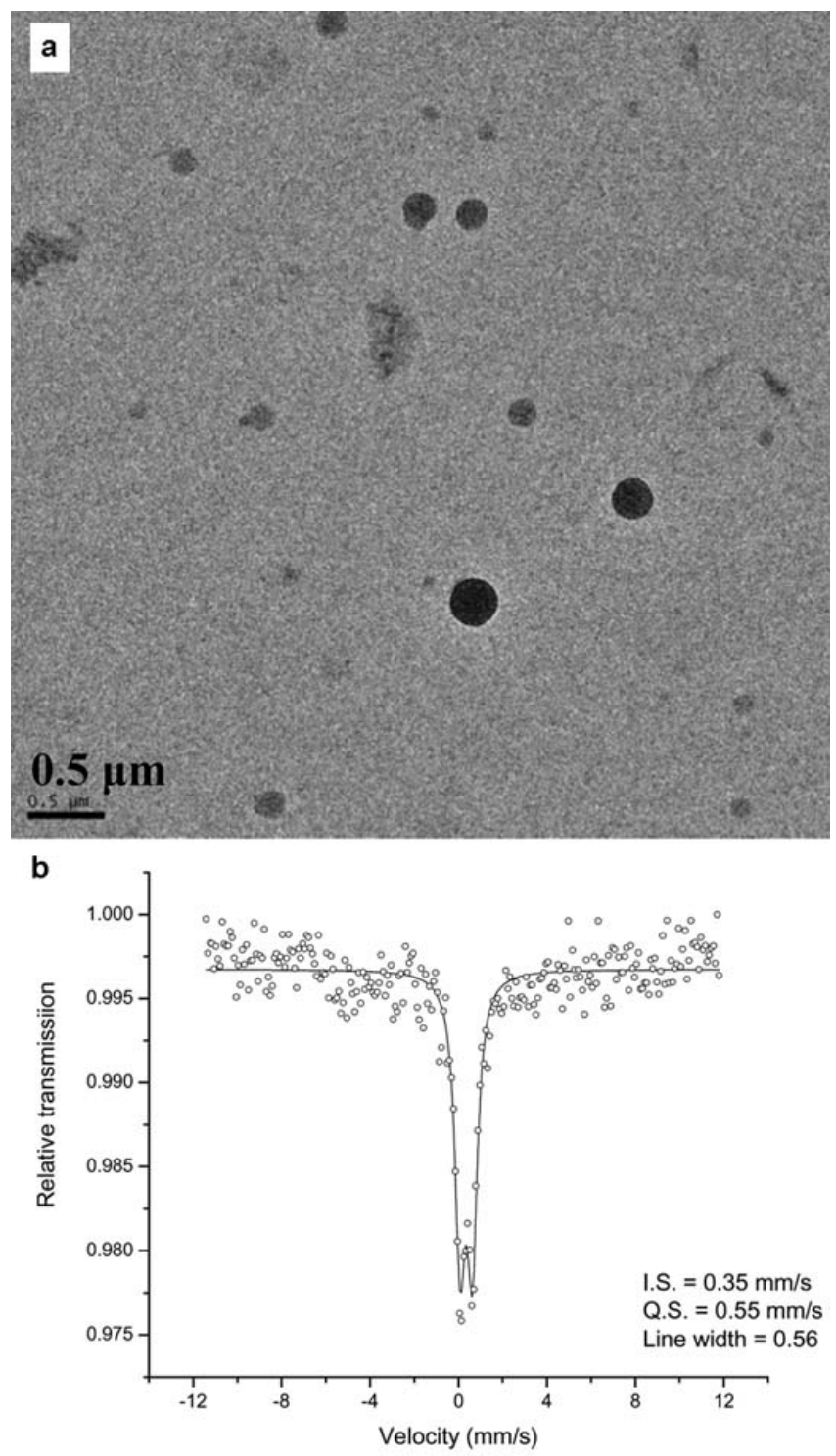

Figure 2. (a) TEM of iron succinate and (b) Mössbauer spectra of iron succinate synthesized using $\mathrm{Fe}\left(\mathrm{NO}_{3}\right)_{3} \cdot 9 \mathrm{H}_{2} \mathrm{O}$ at room temperature. nate were found to be similar to that obtained with $\mathrm{Fe}\left(\mathrm{NO}_{3}\right)_{3}$. The TEM studies show smaller spherical particles of size $\sim 20-30 \mathrm{~nm}$ (figure 3a). Mössbauer studies confirmed the presence of trivalent O.S. of Fe (figure 3b). The large quadrupole splitting (QS) values show significant distortion of the octahedra around Fe atom. From the above studies it appears that though the metal ion was initially in the +2 O.S. $\left(\mathrm{FeCl}_{2}\right)$, it gets oxidized during the preparation of the microemulsion or during the reaction when the two microemulsions were mixed.

The TGA/DTA studies for cobalt succinate in flowing nitrogen shows two sharp weight losses at $130^{\circ} \mathrm{C}$ and at $415^{\circ} \mathrm{C}$. The first weight loss at $130^{\circ} \mathrm{C}$

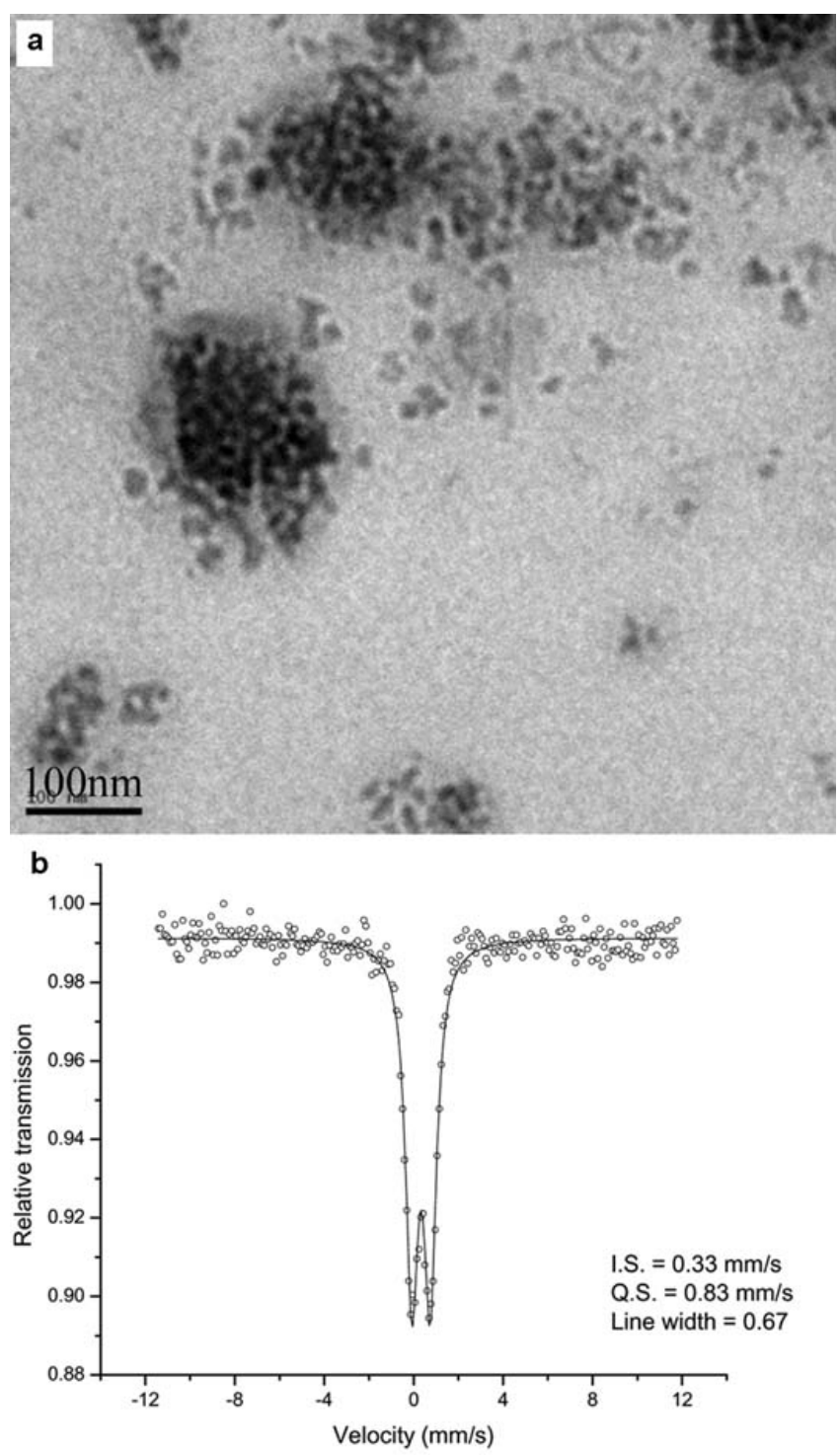

Figure 3. (a) TEM of iron succinate and (b) Mössbauer spectra of iron succinate synthesized using $\mathrm{FeCl}_{2} \cdot 4 \mathrm{H}_{2} \mathrm{O}$. 
corresponds to the loss of one-and-half water molecules. The final weight loss corresponds to the decomposition of cobalt succinate to cobalt nanoparticles. However, the final product was also found to contain some unburnt carbon residue. This is in accordance with the data as obtained by Muraishi et al in their detailed thermal analysis of metal succinates. ${ }^{9}$ Cobalt succinate dihydrate heated at $500^{\circ} \mathrm{C}$ for $6 \mathrm{~h}$ in air yielded pure $\mathrm{Co}_{3} \mathrm{O}_{4}$ (figure 4). All the reflections in the PXRD pattern could be indexed on the basis of a cubic cell for $\mathrm{Co}_{3} \mathrm{O}_{4}$ with refined lattice parameters of $a=8.069$ (3) $\AA$. The crystallite size of $\mathrm{Co}_{3} \mathrm{O}_{4}$ nanoparticles was found to be $\sim 53 \mathrm{~nm}$ by Scherrer's formula while TEM of the same sample shows particles of $\sim 50-60 \mathrm{~nm}$ (figure 5a) and the lattice fringes could be indexed as (222) planes (figure 5b). In the presence of nitrogen at $650^{\circ} \mathrm{C}$, cobalt succinate dihydrate decomposed to yield pure Co nanoparticles (figure 6) with size ranging between 10 and $40 \mathrm{~nm}$ (figure 7).

For iron (III) succinate synthesized from $\mathrm{Fe}\left(\mathrm{NO}_{3}\right)_{3} \cdot 9 \mathrm{H}_{2} \mathrm{O}$, two weight losses were observed in TGA (under nitrogen) at $100^{\circ} \mathrm{C}$ and at $350^{\circ} \mathrm{C}$. The weight loss at $100^{\circ} \mathrm{C}$ corresponds to the loss of 3 moles of water suggesting that a trihydrate complex had formed. From the TGA plot, formation of metal oxides was found to be around $415^{\circ} \mathrm{C}$. Hence, the sample was subjected to heat treatment in the range of 375 to $500^{\circ} \mathrm{C}$ under different atmospheric conditions (air and nitrogen). It was found that when heated in the presence of air at $375^{\circ} \mathrm{C}$, iron succinate gives $\alpha-\mathrm{Fe}_{2} \mathrm{O}_{3}$ (figure $8 \mathrm{a}$ ), yielding cubes of edge length $\sim 180 \mathrm{~nm}$ and some elongated particles of size $\sim 150 \mathrm{~nm}$ (figure $8 \mathrm{~b}$ ). In the presence of nitrogen at

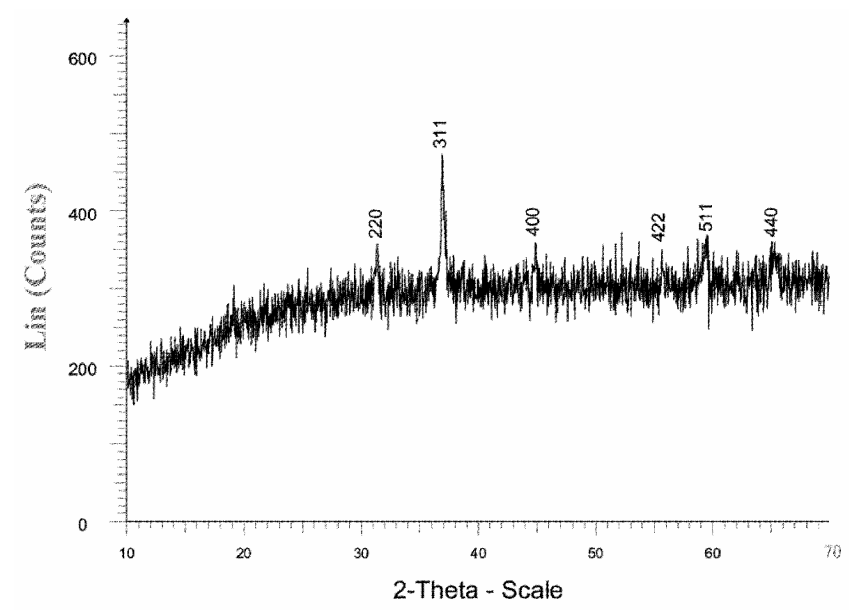

Figure 4. PXRD of $\mathrm{Co}_{3} \mathrm{O}_{4}$ obtained by heating cobalt succinate at $500^{\circ} \mathrm{C}$ in air. $500^{\circ} \mathrm{C}$ it produces a mixture of $\mathrm{Fe}_{3} \mathrm{O}_{4}$ and $\mathrm{Fe}$ (figure 9a) with $\mathrm{Fe}_{3} \mathrm{O}_{4}$ nanoparticles with edge length $\sim 50 \mathrm{~nm}$ (figure $9 \mathrm{~b}$ ). Earlier thermal studies on iron (II) oxalate dihydrate showed sharp transitions at 160 and $410^{\circ} \mathrm{C}$ which led to $\mathrm{Fe}_{2} \mathrm{O}_{3}$ nanoparticles of size $\sim 50 \mathrm{~nm}$ joined together to form $\mathrm{Y}$-junctions in air and faceted grains of $\mathrm{Fe}_{3} \mathrm{O}_{4}$ of size $\sim 60-70 \mathrm{~nm}$ when heated in vacuum.
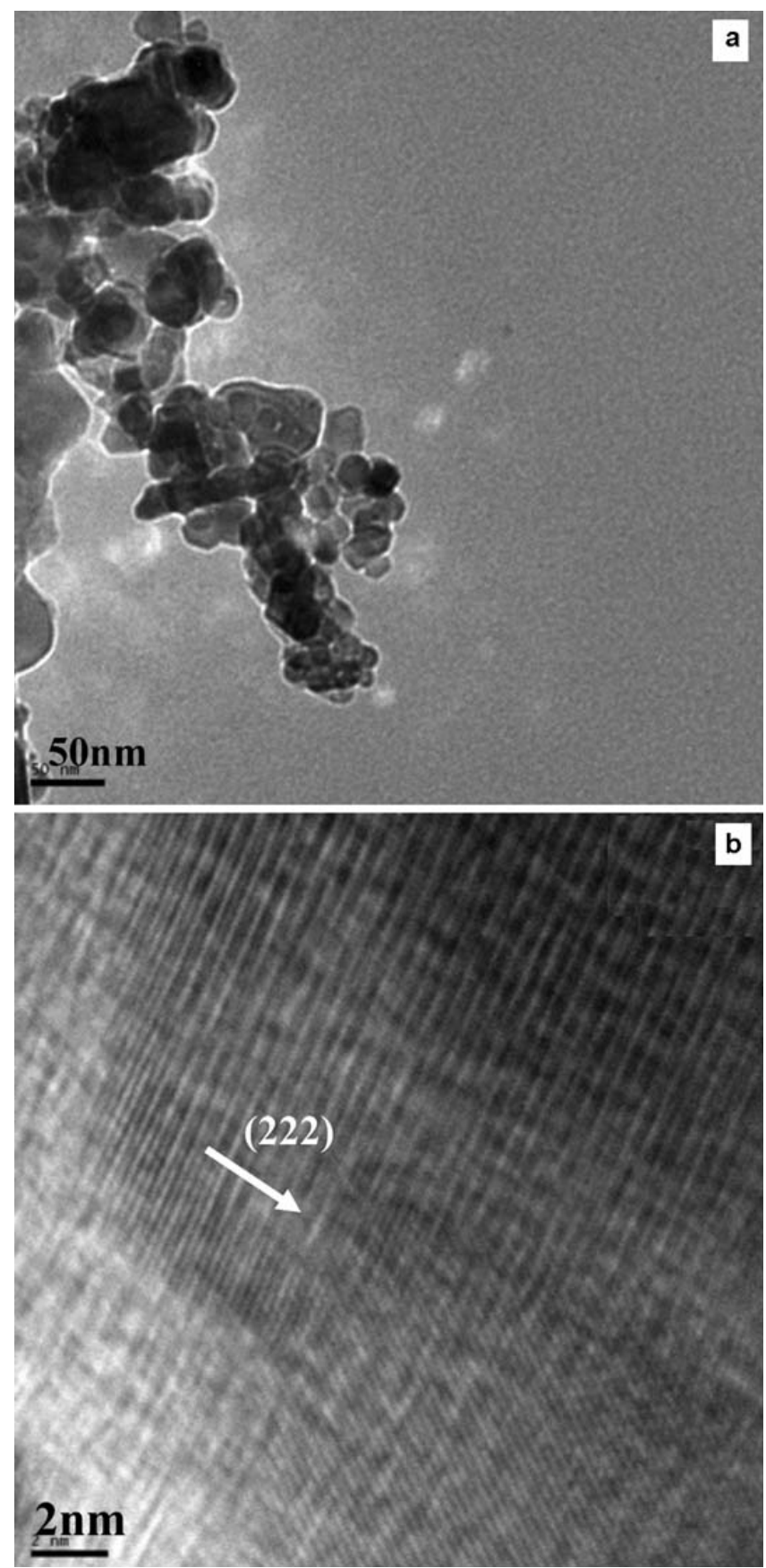

Figure 5. (a) TEM micrograph of $\mathrm{Co}_{3} \mathrm{O}_{4}$ nanoparticles at $500^{\circ} \mathrm{C}$ and (b) $\mathrm{HRTEM}$ of $\mathrm{Co}_{3} \mathrm{O}_{4}$ 
Iron succinate synthesized from $\mathrm{FeCl}_{2} \cdot 4 \mathrm{H}_{2} \mathrm{O}$ shows a gradual decomposition up to $1000^{\circ} \mathrm{C}$ in nitrogen with broad transitions at 200,450 and $970^{\circ} \mathrm{C}$ suggesting a loss of 5 moles of water, and the final product corresponds to formation of elemental iron along with some carbon residue In the presence of nitrogen, the succinate precursor was found to decompose at $800^{\circ} \mathrm{C}$ to pure $\alpha$-Fe (bcc) nanoparticles (figure 10).

We have studied the magnetic properties of the metal succinate and their oxides. Antiferromagnetictype behaviour is observed from the susceptibility

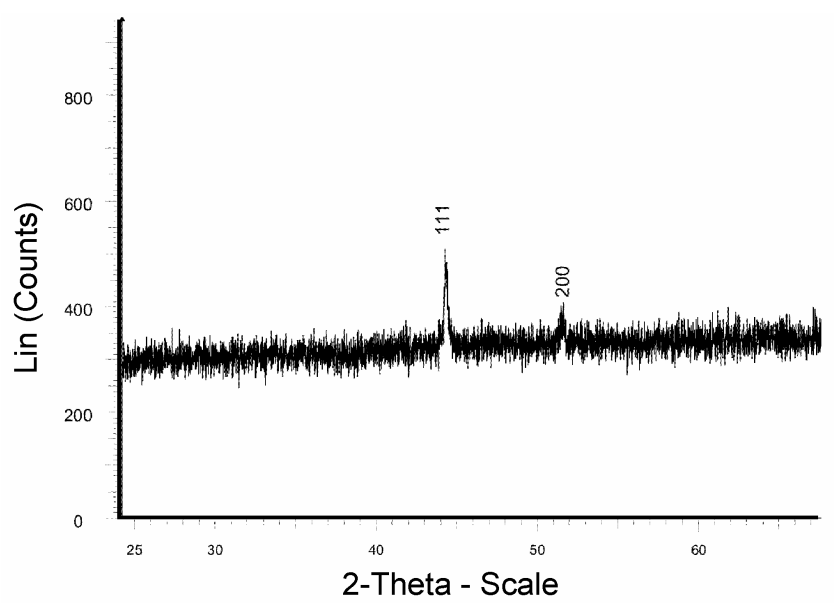

Figure 6. PXRD pattern of Co nanoparticles obtained by heating cobalt succinate at $650^{\circ} \mathrm{C}$ under nitrogen.

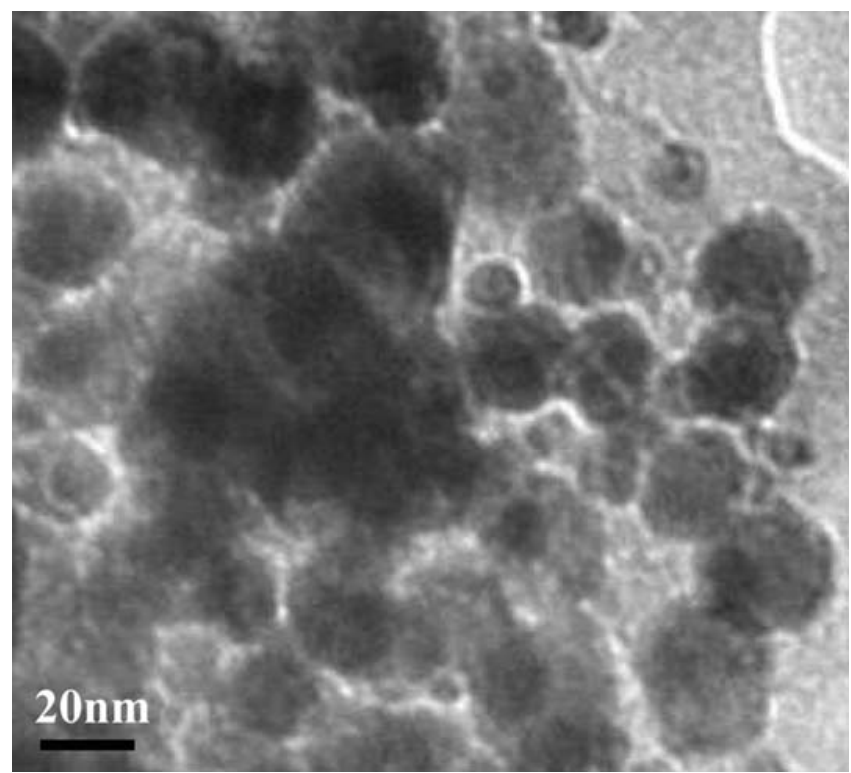

Figure 7. TEM micrograph of Co nanoparticles obtained by heating the cobalt succinate at $650^{\circ} \mathrm{C}$ under nitrogen. plots of cobalt succinate dihydrate (figure 11). The effective magnetic moment $\mu_{\text {eff }}$ calculated from the Curie plot in the range of $100-300 \mathrm{~K}$ is found to be 5.9 Bohr magnetons (B.M.), which is higher than the theoretical value of 3.87 B.M for $\mathrm{Co}^{2+}$. Presumably, the rise at low temperature is due to Curie impurities.

$\mathrm{Co}_{3} \mathrm{O}_{4}$ has a normal spinel structure with $\mathrm{Co}^{2+}$ occupying the tetrahedral position and the $\mathrm{Co}^{3+}$ ion occupying the octahedral position. Since in its low spin configuration, $\mathrm{Co}^{3+}\left(t_{2 g}{ }^{6} e_{g}{ }^{0}\right)$ does not contribute to the magnetic moment, the measured susceptibility arises due to the divalent ion with a $d^{7}$ configuration $\left(t_{2 g}{ }^{5} e_{g}{ }^{2}\right)$. The observed high value of $\mu_{\mathrm{eff}}$ (8.34 B.M.)
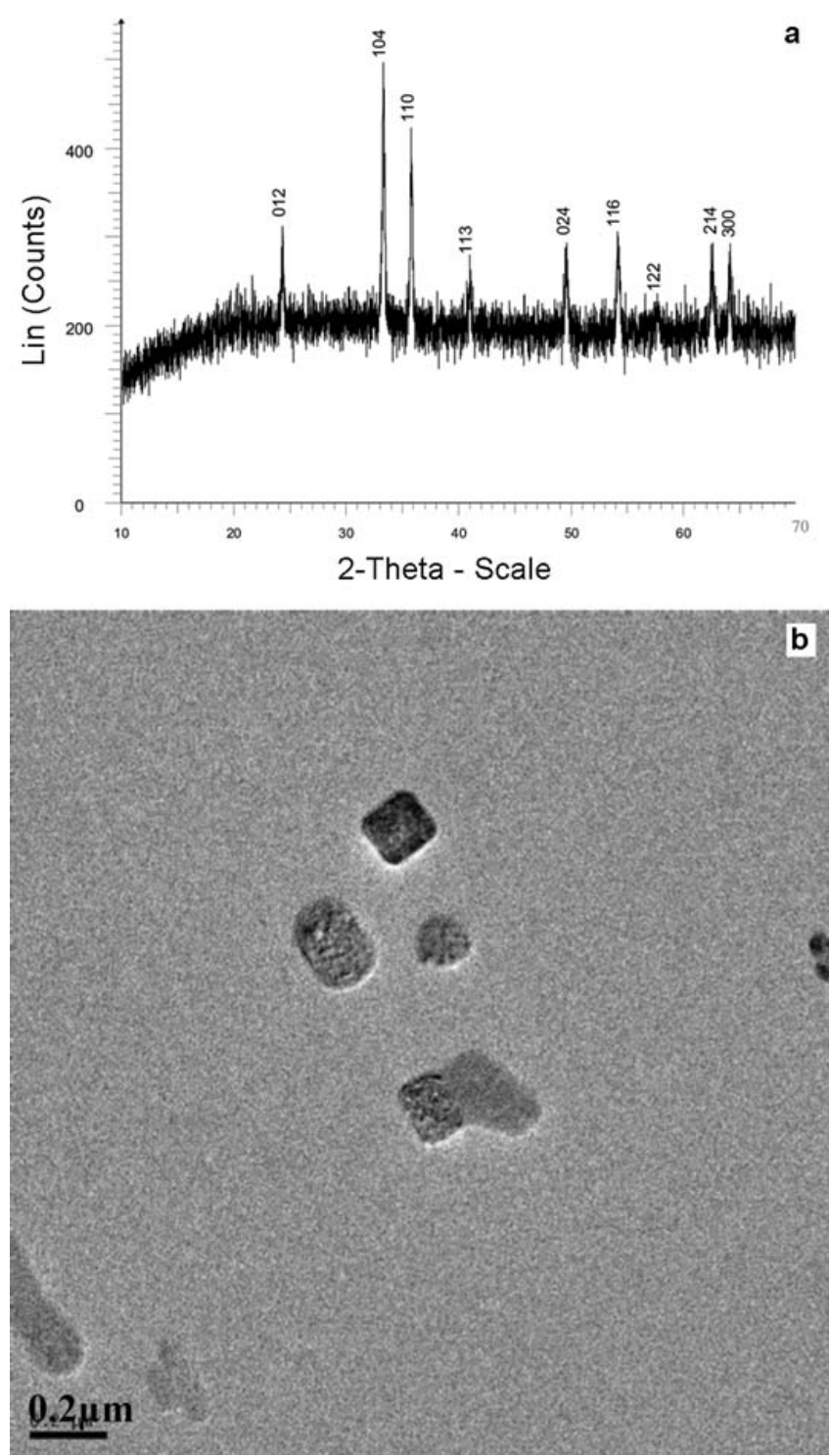

Figure 8. (a) PXRD pattern and (b) TEM micrograph of $\alpha-\mathrm{Fe}_{2} \mathrm{O}_{3}$ nanoparticles obtained by decomposing $\mathrm{Fe}(\mathrm{III})$ succinate at $375^{\circ} \mathrm{C}$ in air. 
has been observed in $\mathrm{Co}_{3} \mathrm{O}_{4}$ nanoparticles by $\mathrm{Ya}$ mada et al, ${ }^{11}$ who attributed it to uncompensated superparamagnetic surface spins and the presence of oxygen defects. Antiferromagnetic ordering occurs at $\sim 20 \mathrm{~K}$ (figure 12). Note that such a transition is reported at $\sim 33 \mathrm{~K}$ for the bulk compound.

$\mathrm{Fe}(\mathrm{III})$ succinate synthesized from $\mathrm{FeCl}_{2} \cdot 4 \mathrm{H}_{2} \mathrm{O}$ shows antiferromagnetic behaviour. The magnetic moment calculated (5.9 B.M.) matches well with the theoretical value (5.9 B.M.) which also corroborates with the Mössbauer studies (figure 13). It is to be noted that electron spin resonance spectra (not shown) display two lines, suggesting more than one Fe site or valence. More detailed structural studies are re-
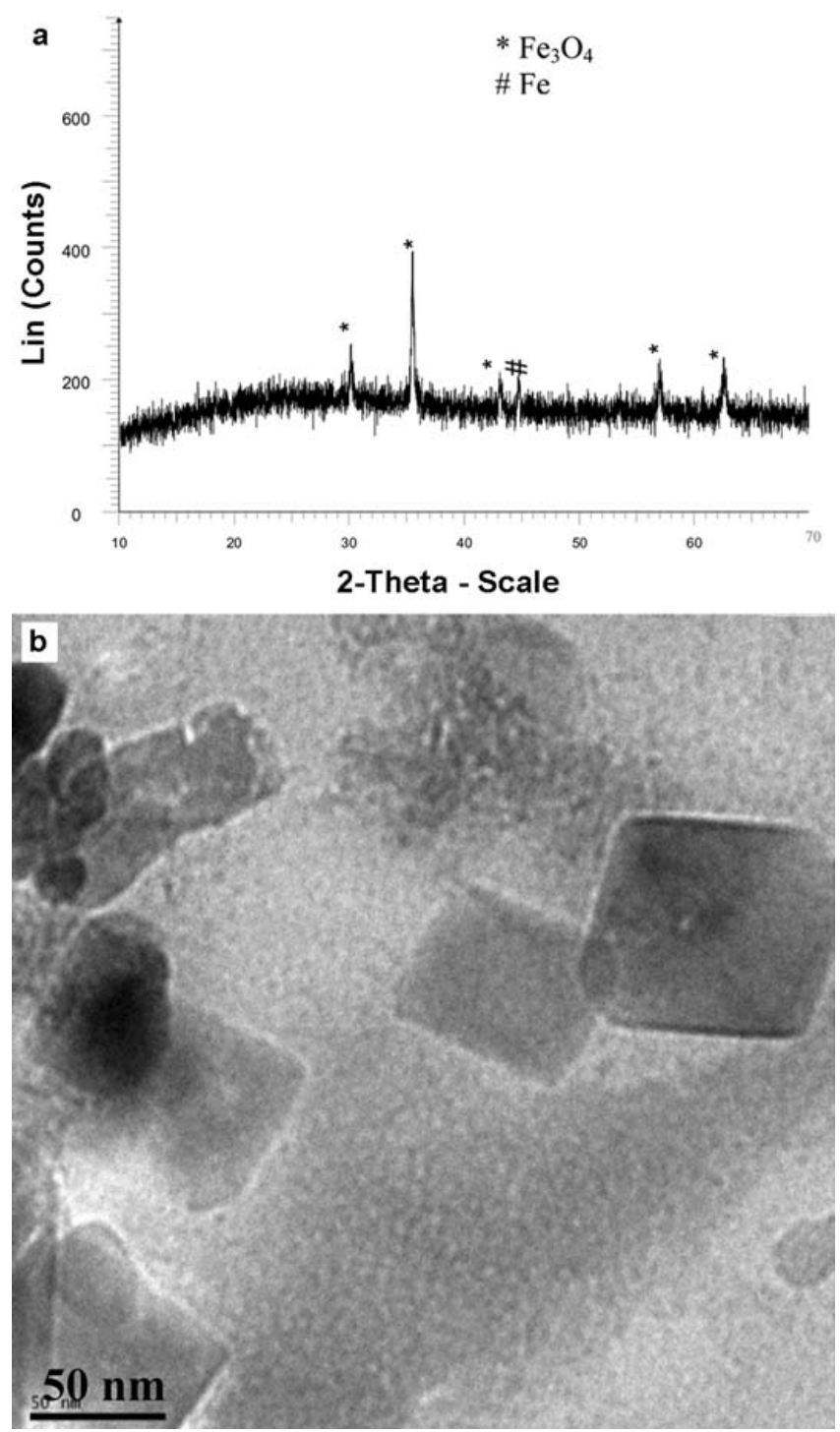

Figure 9. (a) PXRD pattern and (b) TEM micrograph of $\mathrm{Fe}_{3} \mathrm{O}_{4}$ obtained by decomposing $\mathrm{Fe}(\mathrm{III})$ succinate at $500^{\circ} \mathrm{C}$ in nitrogen. quired to understand the arrangement of the $\mathrm{Fe}^{3+}$ in the lattice. The susceptibility of $\mathrm{Fe}$ (III) succinate

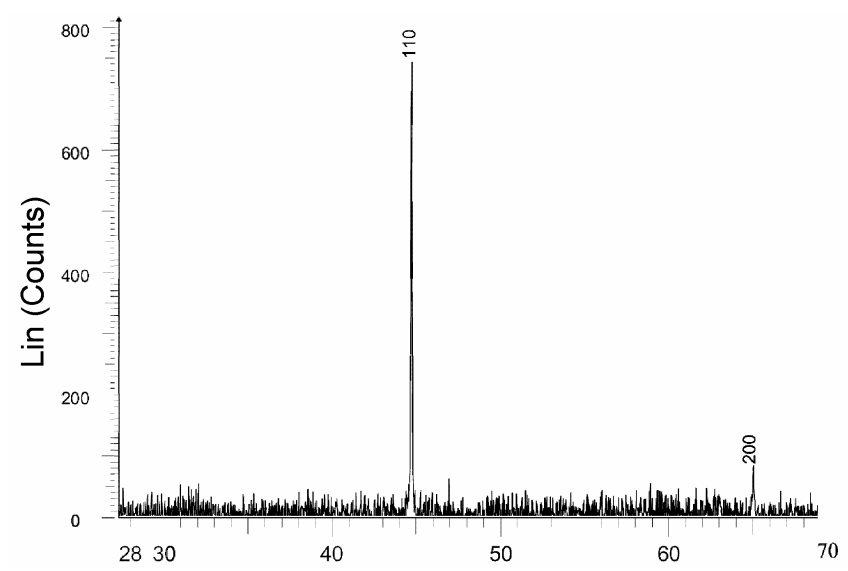

Figure 10. PXRD pattern of Fe obtained by decomposing iron succinate at $800^{\circ} \mathrm{C}$ in nitrogen.

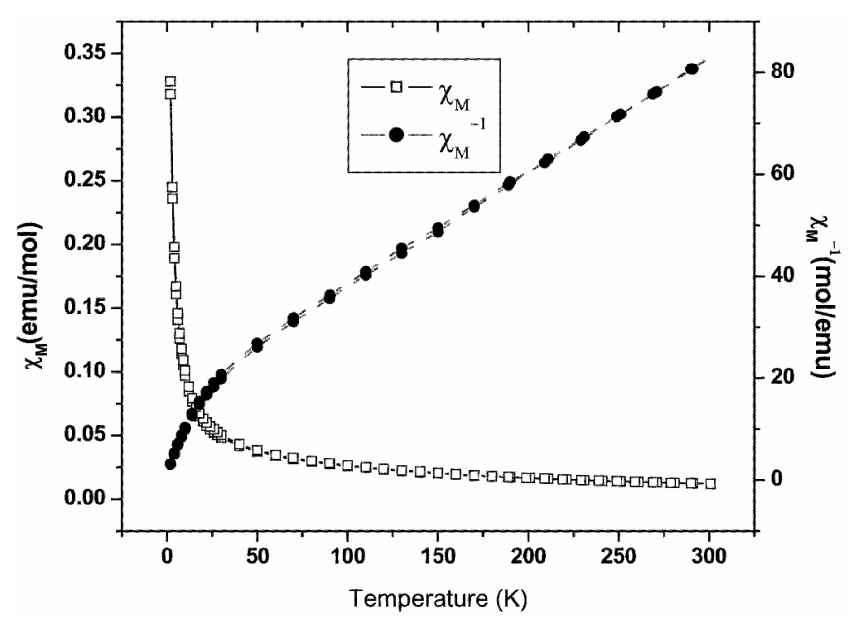

Figure 11. Temperature variation studies of magnetic susceptibility and inverse magnetic susceptibility of cobalt succinate dihydrate.

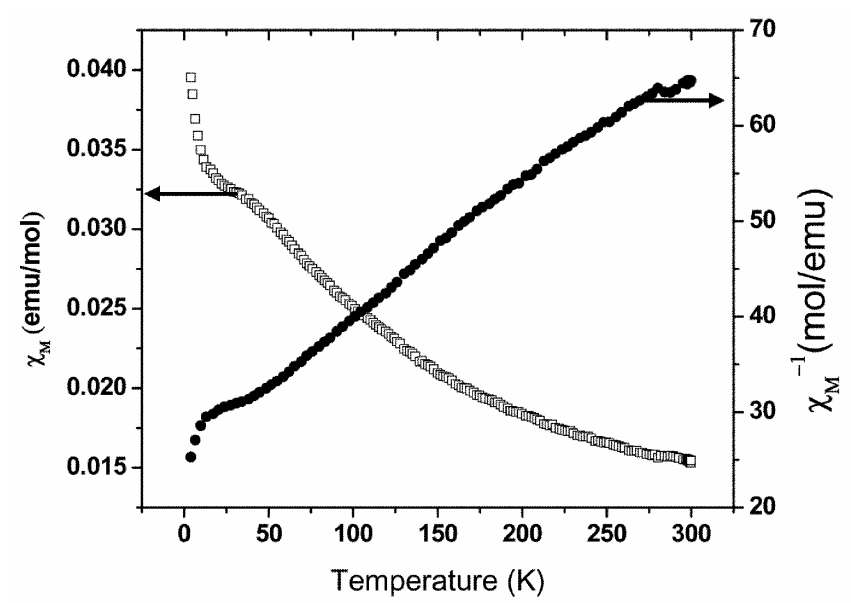

Figure 12. Temperature variation studies of magnetic susceptibility and inverse magnetic susceptibility of $\mathrm{Co}_{3} \mathrm{O}_{4}$ at $0 \cdot 1 \mathrm{~T}$. 
synthesized from $\mathrm{Fe}\left(\mathrm{NO}_{3}\right)_{3}$ also showed antiferromagnetic behaviour (figure 14) although there is an anomalous increase below $50 \mathrm{~K}$. The magnetic moment as calculated from the Curie plot (4.41 B.M.) is lower than that of the calculated theoretical value (5.9 B.M.), assuming $\mathrm{Fe}^{3+}$.

The nano-cubes of $\alpha-\mathrm{Fe}_{2} \mathrm{O}_{3}$, with edge length of $\sim 150 \mathrm{~nm}$, show a weak antiferromagnetic ordering (figure 15) at around $223 \mathrm{~K}$ which is reminiscent of the Morin transition. $\alpha-\mathrm{Fe}_{2} \mathrm{O}_{3}$ single crystals have been reported to show the Morin transition $\left(T_{m}\right)$ from a weakly ferromagnetic solid to a weakly antiferromagnetic solid below $263 \mathrm{~K}^{12}$ The $T_{m}$ shifts to lower temperatures with decrease in particle size which may be due to lattice defects and strains in the small-sized particles. Similar type of transition was

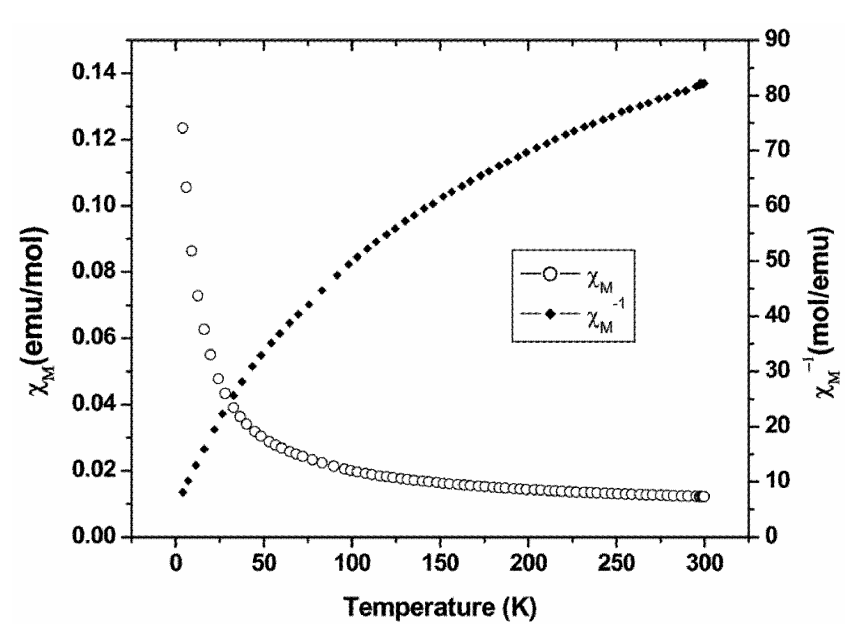

Figure 13. Temperature variation studies of magnetic susceptibility and inverse magnetic susceptibility of iron succinate synthesized using $\mathrm{FeCl}_{2} \cdot 4 \mathrm{H}_{2} \mathrm{O}$

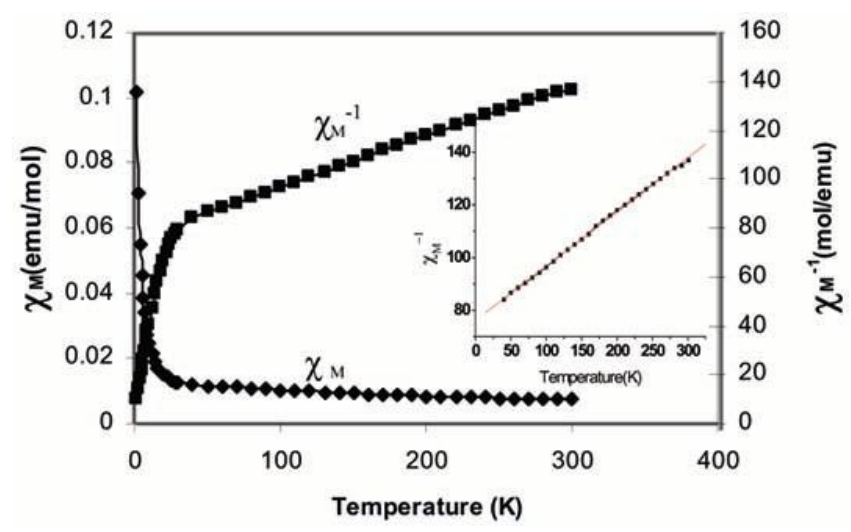

Figure 14. Temperature variation studies of magnetic susceptibility iron succinate trihydrate synthesized using $\mathrm{Fe}(\mathrm{NO})_{3} \cdot 9 \mathrm{H}_{2} \mathrm{O}$. Inset shows the inverse plot of susceptibility vs temperature. observed at $225 \mathrm{~K}$ for the $\mathrm{Fe}_{2} \mathrm{O}_{3}$ nanoparticles obtained from iron oxalate. ${ }^{4}$

$\mathrm{Fe}_{3} \mathrm{O}_{4}$ nanoparticles showed a magnetic transition at $\sim 115 \mathrm{~K}$ (figure $15 \mathrm{~b}$ ). This Verwey transition occurs in bulk $\mathrm{Fe}_{3} \mathrm{O}_{4}$ at $120 \mathrm{~K} .{ }^{13}$ The transition was observed in the case of $\mathrm{Fe}_{3} \mathrm{O}_{4}$ nanoparticles obtained from iron oxalate at $122 \mathrm{~K}^{4}$

The magnetization studies of the Fe nanoparticles show a magnetization of more than $45 \mathrm{emu} / \mathrm{g}$ at room temperature, negligible hysteresis and a lack of saturation, which suggest nearly superparamagnetic behaviour (figure 16).

In comparison to our earlier reports ${ }^{4,8}$ on the synthesis and characterization of metal oxalates, we could observe a distinct change in morphology of the product from nanorods to nanoparticles as we changed the carboxylate anion from oxalate to succinate. Nanorods of iron oxalate dihydrate with an aspect ratio of $\sim 7$ were obtained from oxalates ${ }^{4}$ while only spherical nanoparticles of iron succinate could be synthesized. From the Mössbauer studies, it was confirmed that iron in both the succinate complexes was in trivalent state and hence the formation of nanorods is not favourable. ${ }^{8}$ However, for both the oxalate and succinate precursors of cobalt, nanorods were observed. With the oxalate ligand, mi-
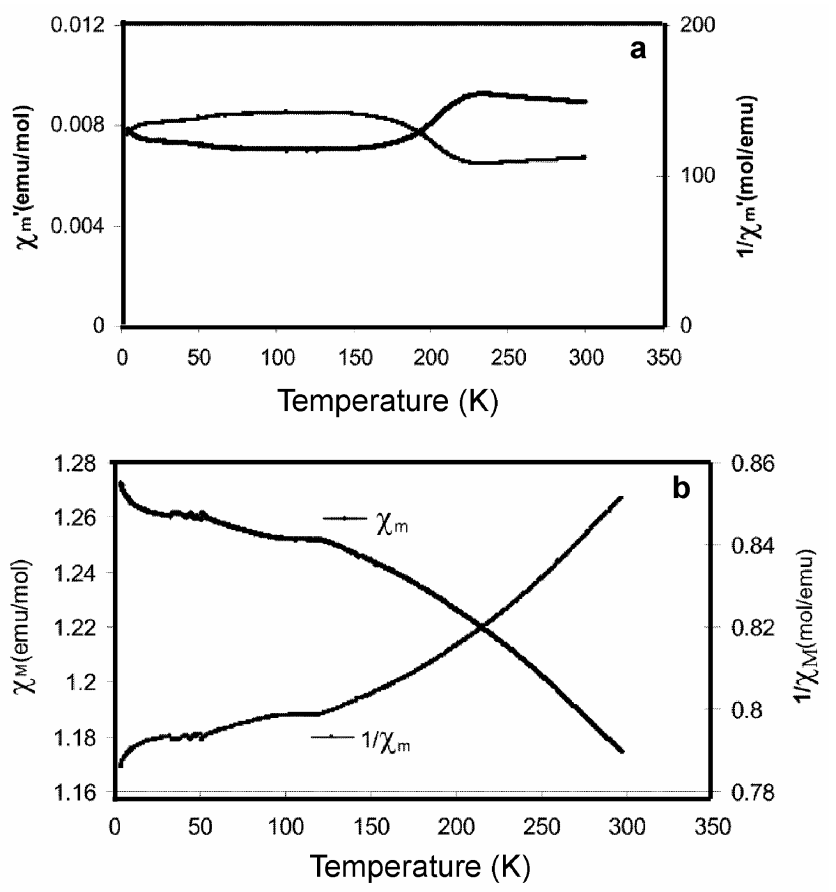

Figure 15. Temperature variation studies of magnetic susceptibility and inverse magnetic susceptibility (a) $\alpha$ $\mathrm{Fe}_{2} \mathrm{O}_{3}$ and (b) $\mathrm{Fe}_{3} \mathrm{O}_{4}$. 


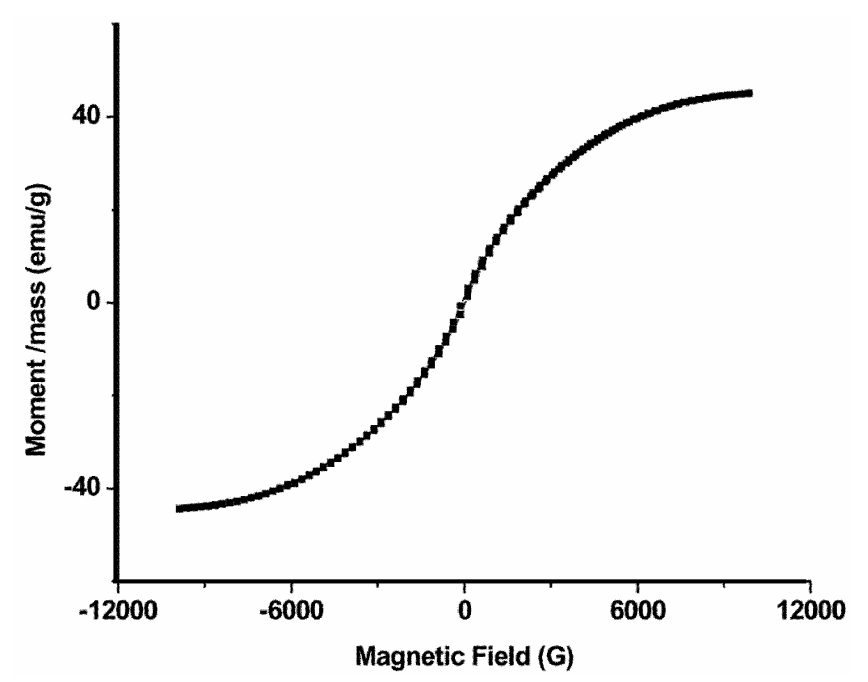

Figure 16. Hysteresis loop for nanoparticles of $\mathrm{Fe}$ at $300 \mathrm{~K}$.

cron-sized rods were formed ${ }^{14}$ while with the succinate anion, shorter rods of few hundred nanometers and $50 \mathrm{~nm}$ diameter were found. Note that in case of bulk cobalt succinate, a dimeric structure is known where the carboxylate group is bonded to two different cobalt atoms to give a tetrahedral environment. ${ }^{3}$ This structural necessity probably leads to shorter rods. Thus it seems that the bidentate succinate ion also favours the formation of rods like the oxalate ion only if the metal ion is in +2 oxidation state as evidenced from the formation of cobalt succinate nanorods.

\section{Conclusions}

Polycrystalline metal-organic hybrid nanostructures were made by the reverse micellar route. Controlled thermal treatment of the succinate precursors under different atmospheric conditions yielded metal and metal-oxide nanoparticles. We find a significant change in particle size for the spherical nanoparticles of iron succinate as we change the reactant metal ion from $\mathrm{Fe}\left(\mathrm{NO}_{3}\right)_{3} \cdot 9 \mathrm{H}_{2} \mathrm{O}(150-200 \mathrm{~nm})$ to $\mathrm{FeCl}_{2} \cdot 4 \mathrm{H}_{2} \mathrm{O}(20-30 \mathrm{~nm})$. A change in the morphology of metal carboxylates was also observed when succinate was used instead of oxalate. Spherical nanoparticles were formed for iron succinate opposed to the nanorods we got for iron oxalate. ${ }^{4} \mathrm{Co}-$ balt oxide $\left(\mathrm{Co}_{3} \mathrm{O}_{4}\right)$ nanoparticles of size $\sim 60 \mathrm{~nm}$ was obtained from the succinate precursor which shows weak antiferromagnetic ordering at $20 \mathrm{~K}$. Nanoparticles of $\alpha-\mathrm{Fe}_{2} \mathrm{O}_{3}$ obtained from iron succinate shows weak antiferromagnetic ordering (Morin transition) at $223 \mathrm{~K}$ which is much lower than that found in bulk $\mathrm{Fe}_{2} \mathrm{O}_{3}$. Nanoparticles of $\mathrm{Fe}_{3} \mathrm{O}_{4}$ have faceted cuboidal shape with a weak Verwey-like transition at $115 \mathrm{~K}$. In addition, a very simple route to obtain nearly $100 \%$ superparamagnetic $\alpha$-Fe nanoparticles was developed from a succinate precursor.

\section{Acknowledgements}

AKG and TA thank the Department of Science and Technology (DST) and Council of Scientific and Industrial Research (CSIR), Government of India for financial support. AG thanks University Grants Commission (UGC) for a fellowship. Thanks to Ms B Bhushan for the analysis of Mössbauer data. SEL acknowledges support from National Foundation of Science (NSF) MRSEC DMR 0520471. KVR appreciates the support of DST, Government of India for the award of a CP-STIO fellowship.

\section{References}

1. Livage C, Egger C and Ferey G 1999 Chem. Mater. 111546

2. Vaidhyanathan R, Natarajan S and Rao C N R 2002 Inorg. Chem. $\mathbf{4 1} 5226$

3. Abd El-Salaam K M, Halawani K H and Fakiha S A 1992 Thermochimica Acta 204311

4. Ganguli A K and Ahmad T 2007 J. Nanosci. Nanotech. 72029

5. Ahmad T, Ramanujachary K V, Lofland S E and Ganguli A K 2004 J. Mater. Chem. 143406

6. Ahmad T, Vaidya S, Sarkar N, Ghosh S and Ganguli A K 2006 Nanotechnology 171236

7. Vaidya S, Ahmad T, Agarwal S and Ganguli A K 2007 J. Am. Ceram. Soc. 90863

8. Ahmad T, Chopra R, Ramanujachary K V, Lofland S E and Ganguli A K 2005 J. Nanosci. Nanotech. 5 1840

9. Yokobayashi H, Nagase K and Muraishi K 1975 Bull. Chem. Soc. Jap. 482789

10. Roth W I 1964 J. Phys. Chem. Solids 251

11. Ichiyanagi Y and Yamada S 2005 Polyhedron 24 2813

12. Morin F.J 1950 Phys. Rev. 819

13. Verwey E J W 1939 Nature 44327

14. Ahmed J, Ahmad T, Ramanujachary K V, Lofland S E and Ganguli A K 2008 J. Colloid Interface. Sci. 321434 